\title{
The content and bioaccessibility of carotenoids from selected commercially available health supplements
}

\author{
A. M. O’Sullivan, Y. C. O'Callaghan, T. P. O’Connor and N. M. O’Brien \\ School of Food and Nutritional Sciences, University College Cork, Ireland
}

The potential health benefits of algae and wheatgrass, due to their vitamins, amino acids, minerals, carotenoids and other bioactive compounds, have been widely reported ${ }^{(1,2)}$. Chlorella (Chlorella) are single-celled green algae and kelp (Laminaria) are multi-celled brown algae. Spirulina (Arthrospira) are a genus of green-blue cyanobacteria of which the species Arthrospira platensis and Arthrospira maxima are utilised as a food supplement. Wheatgrass is obtained from the common wheat Triticum aestivum. The aims of the present study were to measure the content and bioaccessibility of carotenoids from chlorella, kelp, spirulina and wheatgrass supplements.

The supplements were purchased in a local health food store. Each supplement was weighed ( $2 \mathrm{~g})$, homogenised and then subjected to in-vitro digestion ${ }^{(3)}$ to simulate the human gastric and intestinal digestion system. Subsequently, the micelle fractions of the digested material were isolated via ultracentrifugation. Both the undigested and digested samples were saponified and the carotenoid fraction was extracted using hexane. HPLC was used to quantify the carotenoid content of the supplements.

\begin{tabular}{|c|c|c|c|c|c|c|c|c|}
\hline & \multicolumn{2}{|c|}{ Chlorella } & \multicolumn{2}{|c|}{ Kelp } & \multicolumn{2}{|c|}{ Spirulina } & \multicolumn{2}{|c|}{ Wheatgrass } \\
\hline & Food (ng/g) & Micelle (ng/g) & Food (ng/g) & Micelle (ng/g) & Food (ng/g) & Micelle (ng/g) & Food (ng/g) & Micelle (ng/g) \\
\hline Fucoxanthin & 313 & ND & 479 & ND & 731 & ND & 815 & ND \\
\hline Violaxanthin & 1369 & ND & ND & ND & 32 & ND & 538 & 244 \\
\hline Neoxanthin & 1434 & ND & ND & ND & 58 & ND & 376 & 89 \\
\hline Antheraxanthin & 310 & ND & ND & ND & 287 & ND & 541 & 63 \\
\hline Astaxanthin & 441 & ND & ND & ND & 300 & ND & 287 & 67 \\
\hline Lutein & 5640 & 30 & 37 & ND & 381 & 26 & 17760 & 2918 \\
\hline Zeaxanthin & 596 & ND & 809 & ND & 12268 & 605 & ND & ND \\
\hline Alloxanthin & 1323 & ND & ND & ND & 222 & ND & ND & ND \\
\hline$\beta$-Cryptoxanthin & 496 & ND & 50 & 76 & 112 & 21 & ND & ND \\
\hline$\beta$-Carotene & 454 & ND & 80 & ND & 460 & 40 & ND & ND \\
\hline$\alpha$-Carotene & 379 & ND & 63 & ND & 467 & 94 & 64 & ND \\
\hline
\end{tabular}

Values are means for four independent experiments. ND, not detected.

The total content of the carotenoids determined in the present study was highest in wheatgrass $(20.4 \mu \mathrm{g} / \mathrm{g})$ followed by spirulina $(15.3 \mu \mathrm{g} / \mathrm{g})$ and chlorella $(12.7 \mu \mathrm{g} / \mathrm{g})$, the lowest carotenoid content was in kelp $(1.5 \mu \mathrm{g} / \mathrm{g})$. Lutein was the predominant carotenoid in chlorella and wheatgrass, while zeaxanthin was predominant in wheatgrass. Bioaccessibility was lowest for chlorella and only $0.23 \%$ of the total carotenoid content was transferred to the micelle fraction. Both kelp and spirulina had a carotenoid bioaccessibility of approximately $5 \%$. The highest carotenoid bioaccessibility was in wheatgrass, where $16.6 \%$ of the total carotenoid content was transferred to the micelle fraction. Under the conditions of the present experiment, the bioaccessibility of carotenoids from powdered health supplements, with the exception of wheatgrass, is low in comparison with those reported for foods ${ }^{(3)}$.

1. Cornish ML \& Garbary DJ (2010) Algae 25, 155-171.

2. Bar-Sela G, Tsalic M, Fried G et al. (2007) Nutr Cancer 58, 43-48.

3. Jiwan MA, Duane P, O'Sullivan L et al. (2010) J Food Comp Anal 23, 346-352. 